\section{International Scientific Journal Theoretical \& Applied Science}

\author{
p-ISSN: 2308-4944 (print) e-ISSN: 2409-0085 (online) \\ Year: 2015 Issue: $04 \quad$ Volume: 24 \\ Published: 30.04.2015 http://T-Science.org
}

SECTION 1. Theoretical research in mathematics.
Aknur Yersaiynovna Tuimebayeva candidate of physical and mathematical Sciences, Taraz state University named after M.H. Dulati,

Kazakhstan $\underline{\text { akner@mail.ru }}$

Meruert Kuanyshkyzy Sandibekova student,

Taraz state University named after M.H. Dulati,

Kazakhstan m.s.k_meru05@mail.ru

Sholpan Erlepesovna Zhusipbekova teacher, Kazakh National Medical University named after S.D.Asfendiyarov, Kazakhstan Sholpan_80Aeka@mail.ru

\title{
AN INTEGRAL EQUATION WITH A SPECIAL KERNEL
}

Abstract: In this paper we investigate the question of the spectrum and the solvability of equation Volterra under conditions $\lambda \in C$ and $t \in R_{-}+$.

Key words: range, solvability, Volterra integral equation.

Language: English

Citation: Tuimebayeva AY, Sandibekova MK, Zhusipbekova SE (2015) AN INTEGRAL EQUATION WITH A SPECIAL KERNEL. ISJ Theoretical \& Applied Science 04 (24): 252-255.

Soi: http://s-o-i.org/1.1/TAS*04(24)46 Doi: crossef http://dx.doi.org/10.15863/TAS.2015.04.24.46

\section{ОБ ОДНОМ ИНТЕГРАЛЬНОМ УРАВНЕНИИ С ОСОБЫМ ЯДРОМ}

Аннотация: В данной работе исследуется вопрос спектра и разрешимость уравнения Вольтерра при условиях $\lambda \in C$ и $t \in R_{-}+$.

Ключевые слова: спектр, разрешимость, уравнение Вольтерра.

Statement of the problem. Consider the integral equation of Volterra type of the second kind:

$$
\begin{aligned}
\mu(t)-\lambda \int_{0}^{t} \frac{\mu(\tau) d \tau}{\tau^{\alpha}(t-\tau)^{1-\alpha}}=f(t), t \in \mathbb{R}_{+}, \\
0<\alpha<1, \lambda \in \mathbb{C} .
\end{aligned}
$$

We assume that the right-hand side and the solution of equation (1) belong to the class of integrable functions with corresponding weights:

$$
\begin{aligned}
& e^{-t} f(t) \in L_{1}\left(\mathbb{R}_{+}\right), \\
& t^{-\alpha} e^{-t} \mu(t) \in L_{1}\left(\mathbb{R}_{+}\right) .
\end{aligned}
$$

Objective. To investigate the solvability of special Volterra integral equation of the second kind (1) under the conditions (2).

We write the equation (1) in the form

$$
\begin{aligned}
& \qquad \mu(t)-\lambda \int_{0}^{t} \mathcal{K}(t, \tau) \mu(\tau) d \tau=f(t), \\
& t \in \mathbb{R}_{+}, \\
& \text {where } \\
& \mathcal{K}(t, \tau)=\frac{1}{\tau^{\alpha}(t-\tau)^{1-\alpha}}, 0<\tau<t<\infty .
\end{aligned}
$$

Note that the norm of the integral operator defined by the kernel $\mathcal{K}(t, \tau)$ and acting in the space of integrable functions is $\frac{\pi}{\sin \pi \alpha} \neq 0$. The validity of this follows from

$$
\int_{0}^{t} \frac{d \tau}{\tau^{\alpha}(t-\tau)^{1-\alpha}}=B(\alpha, 1-\alpha)=\frac{\pi}{\sin \pi \alpha}>0
$$

If to enter function $\mathrm{k}(\mathrm{z})$ by a formula 


$$
k(z)= \begin{cases}0, & 0<z<1 \\ \frac{1}{(z-1)^{1-\alpha}}, & 1<z<\infty\end{cases}
$$

we can rewrite equation (3) as

$$
\mu(t)-\lambda \int_{0}^{t} k\left(\frac{t}{\tau}\right) \mu(\tau) \frac{d \tau}{\tau}=f(t)
$$

We investigate the homogeneous integral equation and corresponds to (6):

$$
\mu(t)-\lambda \int_{0}^{t} k\left(\frac{t}{\tau}\right) \mu(\tau) \frac{d \tau}{\tau}=0 .
$$

Applying the Mellin transform [7], taking into account the convolution theorem, we obtain

where

$$
\tilde{\mu}(s)[1-\lambda \tilde{k}(s)]=0, s=s_{1}+i s_{2},
$$

$$
\tilde{\mu}(s)=\int_{0}^{\infty} \mu(\tau) \tau^{s-1} d \tau, \operatorname{Re} s>0
$$

image of function $\mu(t)$ and of the kernel has a form

$$
\tilde{k}(s)=\int_{0}^{1} z^{-s-\alpha}(1-z)^{\alpha-1} d z=B(\alpha,-s+1-\alpha),
$$$$
\text { Re } s<1-\alpha,
$$

here $B(x, y)-$ Veta function.

The presence and form of the eigenfunctions of the homogeneous integral equation (7) is determined by the presence and quantity of roots of the equation transcendence

$$
1-\lambda \tilde{k}(s)=0
$$

concerning the complex parameter s.

Investigate in more detail the question of the roots of equation (9), i.e., according to (8) of the equation

$$
\lambda \cdot B(\alpha,-s+1-\alpha)=1
$$

Given the properties of the beta function $B(\alpha, \beta)=B(\beta, \alpha)$ and using its representation as a series [9], we obtain

$$
\begin{aligned}
& B(1-\alpha-s, \alpha) \\
& =\frac{1}{\alpha} \sum_{n=0}^{\infty}(-1)^{n} \frac{\alpha(\alpha-1)(\alpha-2)(\alpha-3) \ldots(\alpha-n)}{n !(n+1-\alpha-s)} \\
& =
\end{aligned}
$$

$$
=\frac{1}{1-\alpha-s}+\sum_{n=1}^{\infty} \frac{b_{n}}{n+1-\alpha-s}
$$

where

$b_{n}=\frac{(1-\alpha)(2-\alpha) \ldots(n-\alpha)}{n !}=\prod_{k=1}^{n}\left(1-\frac{\alpha}{k}\right)>0$.

Thus, the image of the kernel of the integral equation (7) can be represented as follows

$$
B(-s+1-\alpha, \alpha)=\sum_{n=0}^{\infty} \frac{b_{n}}{n+1-\alpha-s}, \quad b_{0}=1 \text {. }
$$

Writing the equation (11) in the form

$$
\frac{1}{\lambda_{1}+i \lambda_{2}}=\sum_{n=0}^{\infty} \frac{b_{n}}{n+1-\alpha-s_{1}-i s_{2}},
$$

obtain the relations

$$
\frac{\lambda_{1}}{|\lambda|^{2}}=\sum_{n=0}^{\infty} b_{n} \frac{n+\left(1-\alpha-s_{1}\right)}{\left(n+1-\alpha-s_{1}\right)^{2}+s_{2}^{2}},
$$

$-\frac{\lambda_{2}}{|\lambda|^{2}}$
$=s_{2} \sum_{n=0}^{\infty} b_{n} \frac{n+\left(1-\alpha-s_{1}\right)}{\left(n+1-\alpha-s_{1}\right)^{2}+s_{2}^{2}}$.

We have the following

Proposition 1. For all values of $s$, such that $\operatorname{Re} s=s_{1}<1-\alpha$, values sum on the right equalities (12) are positive. This means that the value of $\lambda_{1}=\operatorname{Re} \lambda>0$ and $\lambda_{2}=\operatorname{Im} \lambda$ has a sign equal to antipositive sign of number $s_{2}=I m s$.

Justice of the proposition 1 at once follows from representation of Beta function (11), ratios (12) and conditions that to $b_{n}>00$ for $\forall n=0,1,2, \ldots$

Theorem 1. $\forall \lambda$ at $\operatorname{Re} \lambda \geq \frac{\pi}{\sin \pi \alpha}$ homogeneous integral equation (7) has a nontrivial solution of the form $\mu(t)=t^{-s^{*}}$, where $s^{*}$ is defined as the root of the equation (9) and $\operatorname{Re} s^{*}<1-\alpha$. If $\operatorname{Re} \lambda<\frac{\pi}{\sin \pi \alpha}$, then the homogeneous equation (7) has only the trivial solution.

Consider the homogeneous equation (6):

$$
\mu(t)-\lambda \int_{0}^{t} k\left(\frac{t}{\tau}\right) \mu(\tau) \frac{d \tau}{\tau}=f(t) .
$$

Applying to both sides of this equation Mellin transform, we obtain

$$
\tilde{\mu}(s)[1-\lambda \tilde{k}(s)]=\tilde{f}(s),
$$


where $\tilde{k}(s)$ is determined from the equation (8), and $\tilde{f}(s)$ Mellin transform of the function $f(t)$ :

$$
\tilde{f}(s)=\int_{0}^{\infty} f(t) t^{s-1} d t, \quad \text { Re } s>\gamma,
$$

and the parameter $\gamma$ is chosen so that

$$
\int_{0}^{\infty}|f(t)| t^{\gamma-1} d t<\infty .
$$

Thus, a particular solution of equation (6) has the form

$$
\mu(t)=\frac{1}{2 \pi i} \int_{\sigma-i \infty}^{\sigma+i \infty} \frac{\tilde{f}(s)}{1-\lambda \tilde{k}(s)} t^{-s} d s,
$$

here $\gamma<\sigma<1-\alpha$ is chosen so that $1-\lambda \tilde{k}(s) \neq$ 0 for a given value $\lambda$ and the integral is taken along the line $\operatorname{Re} s=\sigma$, parallel to the imaginary axis of the $s$-plane and is understood in the sense of principal value.

Transform a particular solution (13). To do this, we use the relation

$$
\frac{\tilde{f}(s)}{1-\lambda \tilde{k}(s)}=\tilde{f}(s)+\frac{\lambda \tilde{k}(s)}{1-\lambda \tilde{k}(s)} \tilde{f}(s) .
$$

If we now introduce the notation

$$
\tilde{r}(s)=\frac{\tilde{k}(s)}{1-\lambda \tilde{k}(s)},
$$

then, using the convolution formula for the Mellin transform [1], we obtain

$$
\mu(t)=f(t)+\lambda \int_{0}^{\infty} r\left(\frac{t}{\tau}\right) f(\tau) \frac{d \tau}{\tau},
$$

where

$$
\begin{aligned}
r(\theta)=\frac{1}{2 \pi i} \int_{\sigma-i \infty}^{\sigma+i \infty} & \frac{\tilde{k}(s)}{1-\lambda \tilde{k}(s)} \theta^{-s} d s, \quad \gamma<\operatorname{Res} s \\
& <1-\alpha .
\end{aligned}
$$

At $0<\theta<1$ in the contour of integration include a semi-circle, lying in the left half. In this case, if $\operatorname{Re} \lambda>0$, the integrand has a unique singularity at $-s^{*}$, which is a zero of $1-\lambda \tilde{k}(s)$ and a simple pole of the function $\tilde{r}(s)$.

Thus, in the case of $\operatorname{Re} \lambda>0$ we have

$$
r(\theta)=l\left(-s^{*}\right) \theta^{-s^{*}}, \quad 0<\theta<1,
$$

where $l\left(-s^{*}\right)-$ the inverse of the logarithmic derivative of the function $\tilde{k}(s)$ at $s=-s^{*}$ :

$$
l\left(-s^{*}\right)=-\frac{\tilde{k}\left(-s^{*}\right)}{\widetilde{k^{\prime}}\left(-s^{*}\right)} .
$$

Hence, from (14) that a partial solution inhomogeneous integral equation (1) can be written as

$$
\mu(t)=f(t)+l\left(-s^{*}\right) \int_{0}^{t} \frac{\tau^{-s^{*}-1}}{t^{-s^{*}}} f(\tau) d \tau .
$$

For a case $\lambda \in \mathbb{R}$ the statement takes place.

Proposition 2. If setpoint $\lambda_{1}=R e \lambda$ on the half $s_{1}=\operatorname{Re} s<1-\alpha$ function $1-\lambda_{1} \tilde{k}\left(s_{1}\right)$ has a single zero at $\lambda_{1}>0$ and has no zeros at $\lambda_{1}<0$, on the half $s_{1}>1-\alpha$ for any values $\lambda_{1}$ this function has a countable number of zeros.

Theorem 2. For any function $f(t)$ an inhomogeneous integral equation (1) has a solution of class (2):

$$
\begin{gathered}
\mu(t)=f(t)+l\left(-s^{*}\right) \int_{0}^{t} \frac{\tau^{-s^{*}-1}}{t^{-s^{*}}} f(\tau) d \tau+C t^{-s^{*}}, \\
\operatorname{Re} \lambda>0 \\
\mu(t)=f(t)+\int_{0}^{t} \sum_{k=1}^{\infty} l\left(s_{k}^{0}\right) \frac{\tau^{s_{k}^{0}-1}}{t^{s_{k}^{0}}} f(\tau) d \tau, \\
\operatorname{Re} \lambda<0 .
\end{gathered}
$$

Indeed, for $\operatorname{Re} \lambda>0$ we have

$$
\begin{aligned}
& e^{-t} \mu(t) \\
& =e^{-t} f(t)+l\left(-s^{*}\right) \int_{0}^{t} e^{-(t-\tau)}\left(\frac{\tau}{t}\right)^{-s^{*}} e^{-\tau} f(\tau) \frac{d \tau}{\tau} \\
& +C e^{-t} t^{-s^{*}} .
\end{aligned}
$$

We need to show that the integral term belongs $L_{1}\left(\mathbb{R}_{+}\right)$. It follows from inequality

$$
\begin{aligned}
& \left|\int_{0}^{t} e^{-(t-\tau)}\left(\frac{\tau}{t}\right)^{-s^{*}} e^{-\tau} f(\tau) \frac{d \tau}{\tau}\right| \\
& \leq \int_{0}^{t}\left(\frac{\tau}{t}\right)^{-s^{*}}\left|e^{-\tau} f(\tau)\right| \frac{d \tau}{\tau} \text {. }
\end{aligned}
$$

The same holds for the case $\operatorname{Re} \lambda<0$. 


\section{References:}

1. Nakhushev AM (1983) Differentsial'nye uravneniya. 1983. T.19, N1. -pp.86-94.

2. Nakhushev AM (1995) Uravneniya matematicheskoy biologii. Moscow: Vysshaya shkola, 1995. -301 p.

3. Mizokhata S (1977) Teoriya uravneniy s chastnymi proizvodnymi. Moscow: Mir, 1977. $504 \mathrm{p}$.

4. Titmarsh E (1948) Vvedenie v teoriyu integralov Fur'e. Gostekhizdat, Moscow: - L., 1948.

5. Mikhaylov LG (1963) Novyy klass osobykh integral'nykh uravneniy i ego primeneniya $\mathrm{k}$ differentsial'nym uravneniyam s singulyarnymi koeffitsientami. Dushanbe, Izd. AN TadzhSSR, 1963.

6. Stetsenko VY (1964) O prostote maksimal'nogo sobstvennogo znacheniya odnogo integral'nogo operatora. V kn.: Issledovaniya po kraevym zadacham teorii funktsiy i differentsial'nykh uravneniy. Dushanbe, 1964, -133 p.

7. Krasnov ML (1975) Integral equations. Moscow: Nauka, 1975.

8. Polyanin AD, Manzhirov AV (2003) Handbook of Integral Equations. Moscow: FML, 2003, 608 p.

9. Gradshtein IS, Ryzhik IM (1962) Tables of integrals, series and priozvedeny. Moscow: 1962. -1100 p. 